\title{
Self-concocted, curious and creative coping strategies in movement disorders
}

Eoin Mulroy FRACP ${ }^{1}$, Christos Ganos MD ${ }^{1,2}$, Anna Latorre MD ${ }^{1,3}$, Astrid J Terkelsen MD ${ }^{4}$, Bettina Balint MD ${ }^{1,5}$,Pankaj A Agarwal MD ${ }^{6}$

${ }^{7}$, Amit Batla MD ${ }^{1}$, Kailash P Bhatia FRCP ${ }^{1}$

1. Department of Clinical and Movement Neurosciences, Queen Square Institute of Neurology University College London, London, United Kingdom

2. Department of Neurology, Charité, University Medicine Berlin, Germany

3. Department of Human Neurosciences, Sapienza University of Rome, Italy

4. Danish Pain Research Center and Department of Neurology, Aarhus University Hospital, Denmark

5. Department of Neurology, University Hospital, Heidelberg, Germany

6. Movement Disorders Clinic, Department of Neurology, Institute of Neuroscience, Global Hospital Mumbai, India

7. Department of Neurology, KEM Hospital and Seth GS Medical College, Mumbai, India

\section{Corresponding Author:}

Eoin Mulroy

Department of Clinical and Movement Neurosciences, Queen Square Institute of Neurology University College London, London, United Kingdom

e.mulroy@ucl.ac.uk

Declarations of interest: None. All authors have approved the final article

Key Words: Quality of life; Parkinson disease; Dystonia 
Movement disorders comprise a range of physically and emotionally debilitating conditions which profoundly impact daily activities. Most are associated with significant reductions in quality of life (QOL), which itself is a multidimensional construct influenced not only by physical impairment but also by psychological factors, patient resilience, social support and coping strategies. Maintaining maximal QOL in the face of disease-related challenges is a major focus of movement disorder practice. Herein, we illustrate the significant impact which individualized coping strategies can have on one's wellbeing, in the hope that patients and physicians alike will embrace these adjuncts as part of holistic models of care.

Medical professionals are poor at estimating patients' QOL(1). This likely derives from their frequent failure to grasp the distinction between disease and illness(2). Disease is a set of dysfunctional pathophysiologic processes leading to structural or functional abnormalities in body systems. It is something tangible, which can be assessed, quantified and scientifically examined. Illness on the other hand is a perceived change in one's state of being which impacts on function. Illness is linked to disease, but also majorly determined by personality, attitude, coping strategies, social matrix and the cultural milieu( 3,4$)$. In such a way, two different people with identical diseases can experience vastly different illnesses.

Expansion of biomedical technology increasingly pushes physicians to focus on disease, widening the rift between what patients expect (relief from illness) and what the doctor provides- a notion eloquently described by Eisenberg as the 'dysfunctional consequences of the Cartesian dichotomy'(3). Nevertheless, a brief meander through any movement disorder clinic quickly reminds us of the multivariate determinants of illness, and in particular of the important role of coping mechanisms. To an outside observer, the physical consequences of 
many movement disorders can appear overbearing (disease-focused approach). Yet, even severely disabled individuals often display a remarkable ability to cope with disease and lead full, purposeful and enjoyable lives.

Patients know their disease, and often devise pragmatic solutions in order to minimise its impact, exploiting intrinsic disease phenomena e.g. sensory tricks in dystonia using a corset, scarf, variants of pillows and backpacks (figure 1), mechanically overcoming abnormal movements or functional issues e.g. ptosis crutches or whole body cast, and/or devising personalized mitigation strategies(figure 2 and videos). Herein, we illustrate a number of remarkable patient-driven coping strategies which we have observed in clinical practice. Clinical details, and descriptions of the coping strategies are provided in Figures 1 and 2, and in the accompanying videos. All patients gave their written informed consent for publication.

Coping describes the cognitive and behavioural efforts made to master, minimize or tolerate stress and conflict(5). On a simplistic level, it can be considered to involve either problem-focused (active efforts to solve or minimize the consequences of the problem at hand) and/or emotion-focused (anger, denial, worry and rumination) strategies aimed at managing stressful situations(5). The coping strategies detailed herein are all examples of problem-focused coping strategies, which are widely accepted as promoting better adjustment to disease-related alterations than emotion-focused strategies.

To date, no studies have examined whether distinct coping strategies are preferentially employed in different movement disorders. However, this could explain some of the variance in QOL between movement disorders despite similar levels of functional disability(6). The apparent 
over-representation of dystonia patients in our series is interesting. Though this may simply represent a selection bias, disease-related factors may also be at play. In dystonia for example, the ability to creatively exploit sensory tricks intrinsic to the disease, brain connectivity profiles, or indeed relative preservation of cognition and insight may promote use of problem-focused coping strategies $(7,8)$. Conversely, in Parkinson's disease, cognitive decline which invariably accompanies disease progression has been shown to lessen adoption of problemfocused coping strategies, and consequently lower QOL(9). Therapeutic interventions may also change one's preferential coping mechanisms. The use of dopamine agonists in Parkinson's disease promotes extravertedness and creativeness(10), both of which associate with problem-based coping strategies, while deep brain stimulation also appears to alter one's coping approaches(11).

Curative treatments remain an elusive goal for the majority of movement disorders, and symptomatic therapies often provide suboptimal relief. In this setting, self-driven coping strategies can provide significant benefit, generally without side-effects. Patients should be encouraged to take ownership of their illness, working alongside physicians to find their own unique approaches to maximize their ability to function in daily life. Equally, targeting maladaptive coping mechanisms through psychological interventions may significantly impact illness(12). By illustrating these inventive, self-initiated coping strategies we hope that patients will be encouraged to seek out tailored adaptations aimed at relieving distressing symptoms, and that physicians will be prompted to learn from, disseminate, support and actively engage with such behaviours which will positively impact QOL. 


\section{Acknowledgements: Nil}

Funding: This research did not receive any specific grant from funding agencies in the public, commercial, or not-for-profit sectors.

\section{Authors' contributions:}

$1 \mathrm{~A}$, conception and design of the study; $1 \mathrm{~B}$ : acquisition of data; $1 \mathrm{C}$, analysis and interpretation of data.

2A, drafting the article; $2 \mathrm{~B}$, revising it critically for important intellectual content

3, Final approval of the version to be submitted.
$\mathrm{EM} \quad 1 \mathrm{~A}, 1 \mathrm{~B}, 1 \mathrm{C}, 2 \mathrm{~A}, 3$
$\mathrm{CG} \quad 1 \mathrm{~A}, 1 \mathrm{~B}, 1 \mathrm{C}, 2 \mathrm{~B}, 3$
AL $\quad 1 \mathrm{~A}, 1 \mathrm{~B}, 1 \mathrm{C}, 2 \mathrm{~B}, 3$
AJT $1 \mathrm{~B}, 1 \mathrm{C}, 2 \mathrm{~B}, 3$
$\mathrm{BB} \quad 1 \mathrm{~A}, 1 \mathrm{~B}, 1 \mathrm{C}, 2 \mathrm{~B}, 3$
PAA $1 \mathrm{~B}, 1 \mathrm{C}, 2 \mathrm{~B}, 3$
$\mathrm{AB} \quad 1 \mathrm{~A}, 1 \mathrm{~B}, 1 \mathrm{C}, 2 \mathrm{~B}, 3$
$\mathrm{KPB} \quad 1 \mathrm{~A}, 1 \mathrm{~B}, 1 \mathrm{C}, 2 \mathrm{~B}, 3$ 


\section{References}

1. Janse AJ, Gemke RJBJ, Uiterwaal CSPM, van der Tweel I, Kimpen JLL, Sinnema G. Quality of life: patients and doctors don't always agree: a meta-analysis. J Clin Epidemiol. 2004 Jul;57(7):653-61.

2. Seidlein A-H, Salloch S. Illness and disease: an empirical-ethical viewpoint. BMC Med Ethics. 2019 Dec 9;20(1):5.

3. Eisenberg L. Disease and illness Distinctions between professional and popular ideas of sickness. Cult Med Psychiatry. 1977 Apr;1(1):9-23.

4. Zola IK. Culture and Symptoms--An Analysis of Patient's Presenting Complaints. Am Sociol Rev. 1966 Oct;31(5):615.

5. Folkman S, Lazarus RS. An Analysis of Coping in a Middle-Aged Community Sample. J Health Soc Behav. 1980 Sep;21(3):219.

6. Gendre T, Carle G, Mesrati F, Hubsch C, Mauras T, Roze E, et al. Quality of life in functional movement disorders is as altered as in organic movement disorders. J Psychosom Res. 2019 Jan;116:10-6.

7. Nickel T, Scheidt CE, Rayki O, Heinen F, Deuschl G, Wissel J, et al. Spasmodic torticollis - a multicentre study on behavioural aspects III: psychosocial changes and behavioural aspects coping. Behav Neurol. 1996;9(2):89-95.

8. Jahanshahi M. Psychosocial factors and depression in torticollis. J Psychosom Res. 1991 Jan;35(4-5):493-507.

9. Hurt CS, Landau S, Burn DJ, Hindle J V., Samuel M, Wilson K, et al. Cognition, coping, and outcome in Parkinson's disease. Int Psychogeriatrics. 2012 Oct 22;24(10):1656-63.

10. Faust-Socher A, Kenett YN, Cohen OS, Hassin-Baer S, Inzelberg R. Enhanced creative thinking under dopaminergic therapy in Parkinson disease. Ann Neurol. 2014 Jun;75(6):935-42.

11. Montel S, Bungener C. What relation is there between deep brain stimulation and coping strategies in Parkinson's disease? Mov Disord. 2008 Sep 15;23(12):1780-4.

12. Whitworth SR, Loftus AM, Skinner TC, Gasson N, Barker RA, Bucks RS, et al. Personality Affects Aspects of Health-Related 
Quality of Life in Parkinson's Disease via Psychological Coping Strategies. J Parkinsons Dis. 2013;3(1):45-53. 